\title{
"Experience and new developments in implementing ALARA in occupational, public and patient exposures" \\ Summary and recommendations of the 10th european ALARA network workshop
}

\author{
P. CROÜAIL ${ }^{1}$, P. SHAW ${ }^{2}$, F. DROUET ${ }^{1}$
}

(Manuscript reçeived 23 March 2007, accepted 7 April 2007)

\begin{abstract}
The 10th european ALARA network (EAN) workshop took place in Prague (Czech Republic) in September 2006. This was the 10-year anniversary of the EAN, and unlike the previous workshops that addressed a particular ALARA topic, the aim of this workshop was to consider the implementation of the optimisation principle in all domains of activities (nuclear and conventional industry, medical sector, NORM industry). This principle is fundamental to radiation protection, and the workshop drew together key stakeholders to discuss its past, present and future status. The workshop was asked to consider the practical implementation of ALARA, and how this might be improved in the next 10 years. The objectives of the 10th EAN workshop were to review the past evolution of the ALARA concept, internationally, within the $\mathrm{EU}$, and nationally, in terms of the practical impact on radiation protection; to examine the current status of the implementation of the ALARA principle; and to identify needs for future developments in the concept and implementation of optimisation. As with previous workshops, half the programme time was devoted to invited presentations, and half to working group discussions and report backs. After discussion, the output of these working groups was collated by the EAN co-ordinators, to produce seven formal recommendations to international organizations (IAEA, International Labour Organisation, European Commission), to EAN itself and to national authorities. These recommendations deal with justification of practices, holistic approach, ALARA culture, ALARA training, especially in the medical sector, ALARA focus through inspection and control, and stakeholder involvement. Individual presentations (papers and slides) are available to download from the EAN website (http://www.eu-alara.net).
\end{abstract}

Keywords: ALARA / personnel / population / patient / recommendation

RÉSUMÉ «Expérience et nouveaux développements dans l'application d'ALARA pour les expositions professionnelles, du public et des patients ». Résumé et recommandations du $10^{\mathrm{e}}$ séminaire du réseau ALARA européen.

${ }^{1}$ CEPN, 28 rue de la Redoute, 92260 Fontenay-aux-Roses, France.

${ }^{2}$ HPA, Radiation Protection Division, Occupational Services Dept., Hospital Lane, Cookridge, Leeds LS 16 6RW, UK. 
Le $10^{\mathrm{e}}$ séminaire du réseau ALARA européen (EAN) s'est déroulé à Prague (République tchèque) en septembre 2006. C'était le $10^{\mathrm{e}}$ anniversaire d'EAN, et contrairement aux séminaires précédents qui traitaient d'une thématique ALARA particulière, le but de ce séminaire était de considérer l'application du principe d'optimisation de la radioprotection dans tous les domaines d'activité (industries nucléaire et non nucléaire, secteur médical, industries utilisant des matériaux naturellement radioactifs). Il s'agit d'un des principes fondamentaux de la radioprotection et ce séminaire a donné l'occasion aux parties prenantes clés de discuter de sa situation passé, actuelle et future. Le séminaire devait notamment traiter l'application pratique du principe ALARA et comment ceci pourrait être amélioré dans les dix ans à venir. Les objectifs de ce $10^{\mathrm{e}}$ séminaire étaient de faire une revue de l'évolution passée du concept ALARA, dans l'Union européenne et dans les pays membres, en termes d'impact pratique sur la radioprotection; d'examiner la situation actuelle de l'application de principe ALARA ; et d'identifier les besoins pour les développements futurs. Comme lors des séminaires précédents, la moitié du programme était consacrée à des présentations orales invitées et l'autre moitié à des travaux en groupe sur des thématiques précises. Après discussion avec l'ensemble des participants au séminaire, les conclusions de ces groupes de travail furent retravaillées par les co-ordinateurs du réseau EAN pour finalement produire sept recommandations destinées à certaines organisations internationales (AIEA, Bureau international du travail, Commission européenne), au réseau EAN lui-même et aux autorités nationales. Ces recommandations traitent de la justification des pratiques, de l'approche holistique des risques, de la culture ALARA, des formations ALARA, en particulier dans le domaine médical, d'ALARA à travers l'inspection et le contrôle et de l'implication des parties prenantes. L'ensemble des présentations individuelles (papiers et diapositives) peuvent être téléchargées sur le site Internet du réseau EAN (http://www.eu-alara.net).

\section{Workshop objectives and programme}

This was the 10-year anniversary of the European ALARA Network, and unlike the previous workshops that addressed a particular ALARA topic, the aim of this workshop was to consider the implementation of the optimisation principle in all domains of activities (nuclear and conventional industry, medical sector, NORM $^{3}$ industry). This principle is fundamental to radiation protection, and the workshop drew together key stakeholders to discuss its past, present and future status. The workshop was asked to consider the practical implementation of ALARA, and how this might be improved in the next 10 years.

The objectives of the 10th EAN workshop were to:

- review the past evolution of the ALARA concept, internationally, within the EU, and nationally, in terms of the practical impact on radiation protection;

- examine the current status of the implementation of the ALARA principle; and

- identify needs for future developments in the concept and implementation of optimisation.

\footnotetext{
${ }^{3}$ Naturally Occurring Radioactive Materials.
} 
As with previous workshops, half the programme time was devoted to invited presentations, and half to working group discussions and report backs, so that all participants could consider the objectives, contribute to discussions, and formulate the final recommendations of the workshop.

In total, there were 23 invited oral presentations, as well as a number of poster presentations, organised under the following titles:

- introduction and setting the scene;

- identifying needs for future development; and

- ALARA implementation in different sectors - problems to be solved.

Two afternoon sessions were set aside for working group discussions, based on the following four topic areas:

- how to encourage the involvement of different stakeholders in implementing ALARA;

- how to further develop ALARA culture (including education and training);

- how to assess ALARA implementation (including performance indicators); and

- how ALARA interfaces with the justification principle, and with other types of risk management.

The reports from the groups were presented and discussed on the final day, from which the key findings and recommendations from the workshop were derived.

Individual presentations (papers and slides) are available to download from the EAN website (http://www.eu-alara.net/). From these, and the discussions that followed, a number of significant themes and issues emerged, and these are described below.

\section{Themes and issues arising}

The introductory and scene-setting session contained keynote presentations from ICRP on the content of its draft recommendations (Holm and Weiss, 2006), IAEA (Deboodt and Mrabit, 2006), EC and EAN (Croft et al., 2006). Together with subsequent presentations from ILO (Niu et al., 2006), UNSCEAR (Crick, 2006), ESOREX (Petrová et al., 2006), EFNDT ${ }^{4}$ (Ewert et al., 2006), EFOMP (Hernandez Armas, 2006), ECRRT ${ }^{6}$ (Katsifarakis, 2006), these provided an

\footnotetext{
${ }^{4}$ European Federation for Non-Destructive Testing.

${ }^{5}$ European Federation of Organisations of Medical Physics.

${ }^{6}$ European Committee of Radiographers and Radiological Technologists.
} 
excellent international overview of the evolution of the ALARA principle and of its implementation. EAN has always aimed to bring together a wide range of stakeholders, and the extended involvement of international organisations throughout the workshop was considered especially valuable.

The presentations in the following two sessions provided a multi-angle analysis of the implementation and application of ALARA in practice. This included assessments of ALARA successes and failures from different stakeholders (regulators, licensees, workers, etc.), and from the perspective of different work sectors such as medical (Hernandez Armas, 2006; Katsifarakis, 2006; Pedersen and Saxebøl, 2006), NDT (Ewert et al., 2006) or NORM (Shaw and Van der Steen, 2006). Also considered was how ALARA fits into the wider protection philosophy, both radiological and non-radiological (Morley, 2006; Niu et al., 2006).

From the presentations and subsequent discussions a number of themes emerged. In terms of looking back over the last 10 years:

- the ALARA principle is firmly embedded within radiation protection culture, and in many sectors there is evidence of progress both in terms of dose restriction and the ways in which the principle is applied in practice. Having said this, there are still some sectors where evidence of progress is lacking, either because ALARA culture has not fully developed (e.g. NDT and NORM), or has not kept pace with developments in that sector (e.g. Medical);

- a number of key issues related to the further evolution of ALARA have emerged in the last few years. These include the role of networking, how to increase stakeholder involvement, the importance of education and training in establishing an ALARA culture, and the integration of ALARA into a wider safety management philosophy ("the holistic approach").

In terms of looking forward to the next 10 years, the following issues were identified:

- the concept and application of networking should continue to be developed. Forging new links with stakeholders, and encouraging the sharing of information on good practice remain key objectives. In particular, EAN should develop links with EFNDT, ESR ${ }^{7}, \mathrm{EFOMP}, \mathrm{ECRRT}, \mathrm{EUTERP}^{8}$ as well as with other regional ALARA networks (i.e. RECAN $^{9}$ ). Specific networks, for regulatory inspectors, research reactors, NORM, NDT, and medical are supported;

\footnotetext{
${ }^{7}$ European Society of Radiology.

${ }^{8}$ European Training and Education in Radiation Protection Platform.

${ }^{9}$ Regional East European and Central Asian Countries ALARA Network (funded by IAEA).
} 
- in the draft ICRP recommendations, the application of ALARA to existing exposure situations has been further developed. Consequently, there is work to be done in terms of how ALARA should be implemented in practice in such situations. ICRP have also developed and expanded the concept of constraints/reference levels - these are intimately linked with ALARA, and the practical outcome of the ICRP recommendations needs further consideration;

- in the medical sector there have been rapid developments in terms of the emergence of new or improved diagnostic and therapeutic techniques involving ionising radiation. More than ever, there is a need for the radiation protection community to become actively engaged with the medical community to ensure that the ALARA principle remains a key consideration.

\section{Workshop recommendations}

Each working group produced conclusions and recommendations, and gave a report back on the final day of the workshop. The output of the working groups was collated by the EAN co-ordinators, to produce the formal recommendations of the workshop, as listed below.

\section{Recommendation 1: Justification of practices}

It is recommended that national authorities should periodically re-evaluate the justification of existing practices. This re-evaluation should consider alternative practices or procedures which could give rise to lower radiation risks. The old practice, or procedure, may be reclassified as no longer being justified, and then abandoned.

It is recommended that the EC consider including this in the next revision of the Basic Safety Standards Directive as a "shall" requirement instead of a "may" requirement ${ }^{10}$ (EC, 1996).

\section{Recommendation 2: Holistic approach}

Radiation protection authorities and occupational health and safety authorities should work together in establishing an overall safety culture. This could be extended to environmental safety aspects. On an operational level, the consideration and implementation of all safety issues, whether radiological, chemical or conventional, should be recognised and addressed as being interdependent, in order to assure a holistic approach in establishing global safety goals.

${ }^{10}$ Article 6.2. "Existing classes or types of practice may be reviewed as to justification whenever new and important evidence about their efficacy or consequences is acquired". 


\section{Recommendation 3: ALARA culture}

Despite the wide acceptance of the need for an ALARA culture, there is no universally agreed definition of what this is. To further the understanding of this concept, it is recommended that EAN propose - and publish on its website - an expanded definition of "ALARA culture". This definition should focus on what the concept means in practice, in terms of the protection framework, and the state of mind and attitudes to be taken up and shared by all stakeholders involved in radiation safety management.

\section{Recommendation 4: ALARA training}

There is a need to generally improve the integration of ALARA into the training of all stakeholders (nuclear and non-nuclear workers, safety inspectors, etc.). At the national level, regulatory bodies should stimulate procedures for the establishment of a framework for ALARA in education and training. International Organisations (EC, IAEA, and ILO) should stimulate the development and coorganisation of syllabi for radiation protection, and foster and support ALARA programmes in specific areas such as medicine, NORM, industrial radiography, etc.

\section{Recommendation 5: Training in the medical sector}

All personnel involved in prescribing and delivering medical exposures should receive appropriate training, so as to understand the risks associated with such exposures, and the need to apply the principles of justification and optimisation of protection in each case. This is relevant both in terms of initial training and programmes for continued professional development.

At a national level, those stakeholders responsible for the provision of education and training in the medical sector should aim to increase the amount of effort devoted to radiation protection in general, and ALARA in particular. Such stakeholders should ensure that these topics are embedded in both initial and ongoing education and training programmes.

Appropriate education and training programmes should be targeted at all personnel involved in prescribing and delivering medical exposures, and should make each group aware of their individual responsibilities. The European medical ALARA network (EMAN) and the EUTERP platform should work together to establish internationally agreed criteria for training and education programmes in this area.

\section{Recommendation 6: ALARA focus through inspection and control}

Regulatory bodies have an important role to play in encouraging ALARA, and should do this through a combination of guidance and enforcement. They should 
ensure that assessing ALARA implementation is an integral part of regulatory inspections. To facilitate this, regulatory bodies should provide guidance to licensees/employers on what types of evidence of ALARA implementation inspectors might expect to see.

Their role is especially important in sectors where ALARA implementation may need further development, such as with NORM, radon, and emerging medical exposure technologies and techniques. Regulatory bodies should give priority to such areas, and ensure that their resources are allocated appropriately.

\section{Recommendation 7: Stakeholder involvement}

EAN should take positive steps to address the issue of stakeholder involvement, especially workers, as identified in this and previous workshops. In particular, EAN should:

- establish a working group to specifically consider workers involvement in occupational exposure management;

- contribute to discussion on a code of conduct currently being prepared by British, French and Spanish RP societies (for IRPA); and

- collect and disseminate examples of stakeholders' involvement in radiation protection.

Regulatory bodies have an important role to play in facilitating stakeholder involvement, and are encouraged to establish mechanisms for communicating with relevant parties and encouraging their participation. This may, for example include, seminars, consultation exercises, public meetings, internet forums, etc.

\section{REFERENCES}

Crick M. (2006) Introduction to public exposure trends and problems to be solved. In: Experience and new Developments in Implementing ALARA in Occupational, Public and Patient Exposures, September 12-15, 2006, Prague.

Croft J., Lefaure C., Janssens A., Schnuer K., Kelly N. (2006) Evolution of ALARA in Europe from the 80 s to the next decade. In: Experience and new Developments in Implementing ALARA in Occupational, Public and Patient Exposures, September 12-15, 2006, Prague.

Deboodt P., Mrabit K. (2006) IAEA perspective on implementation of ALARA principle. In: Experience and new Developments in Implementing ALARA in Occupational, Public and Patient Exposures, September 12-15, 2006, Prague.

EC (1996) European Commission, Council Directive 96/29/EURATOM of 13 May 1996 laying down basic safety standards for the protection of the health of workers and the general public against the dangers arising from ionizing radiation, May 1996, Article 6.2.

Ewert U., Sötter B., Redmer B., Zscherpel U., Purschke M. (2006) ALARA principles in NDT: reduction of radiation exposure by modern methods and detectors. In: Experience and new Developments in Implementing ALARA in Occupational, Public and Patient Exposures, September 12-15, 2006, Prague. 
Hernandez Armas J. (2006) Training and culture problems to be solved in the medical area for improving ALARA implementation. In: Experience and new Developments in Implementing ALARA in Occupational, Public and Patient Exposures, September 12-15, 2006, Prague.

Holm L.E., Weiss W. (2006) Optimisation in ICRP recommendations - new development broadening the process. In: Experience and new Developments in Implementing ALARA in Occupational, Public and Patient Exposures, September 12-15, 2006, Prague.

Katsifarakis D. (2006) The role of radiological technologists in ALARA implementation and the influence of MED 97/43 on that. In: Experience and new Developments in Implementing ALARA in Occupational, Public and Patient Exposures, September 12-15, 2006, Prague.

Morley B. (2006) Holistic approach for risk management with regards to public doses from discharges. In: Experience and new Developments in Implementing ALARA in Occupational, Public and Patient Exposures, September 12-15, 2006, Prague.

Niu S., Repacholi M.H., Deboodt P. (2006) Occupational risk: introduction to an holistic approach including radiological protection. In: Experience and New Developments in Implementing ALARA in Occupational, Public and Patient Exposures, September 12-15, 2006, Prague.

Pedersen K., Saxebøl G. (2006) Quality control and optimisation of patient doses and image quality in the Norwegian mammography screening programme. In: Experience and new Developments in Implementing ALARA in Occupational, Public and Patient Exposures, September 12-15, 2006, Prague.

Petrová K., Frasch G., Schnuer K. (2006) Introduction to occupational exposure trends in Europe and problems to be solved: European Studies on Occupational Radiation Exposures. In: Experience and new Developments in Implementing ALARA in Occupational, Public and Patient Exposures, September 12-15, 2006, Prague.

Shaw P., Van der Steen J. (2006) ALARA and NORM: problems to be solved. In: Experience and new Developments in Implementing ALARA in Occupational, Public and Patient Exposures, September 12-15, 2006, Prague. 